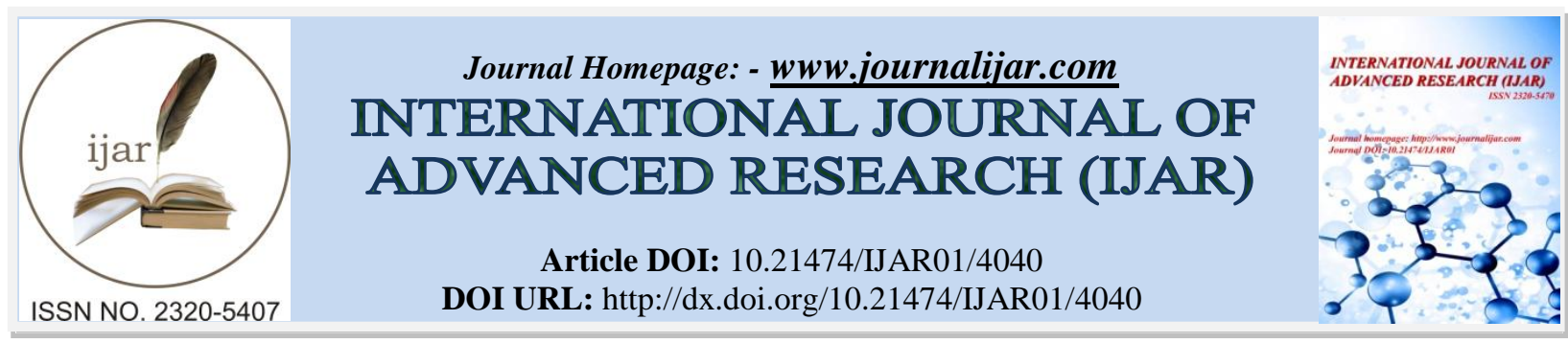

RESEARCH ARTICLE

\title{
BREAST RELATED FACTORS LEADING TO EARLY TERMINATION OF BREASTFEEDING AND THE BENEFITS OF EARLY INITIATION IN THE POST-NATAL WARDS OF A TERTIARY CARE CENTER.
}

\section{Dr. Kaki Sujatha ${ }^{1}$, Dr. Gummadi Vandana Ushasri ${ }^{2}$, Dr. R. Raghupathi ${ }^{3}$ and Akhil Kathi ${ }^{4}$.}

1. M.D (Paediatrics),Associate Professor of Paediatrics. Osmania Medical College and Hospital, Hyderabad, Telangana, India.

2. M.D (Paediatrics), Assistant Professor of Pediatrics, Gandhi Medical College and Hospital, Secunderabad Telangana, India.

3. M.D (Paediatrics),Senior Resident, Department of Pediatrics, Gandhi Medical College and Hospital, Secunderabad Telangana, India.

4. House Surgeon, Gandhi Medical College and Hospital, Secunderabad, Mediciti Institute of Medical Sciences, Hyderabad.

\section{Manuscript Info}

\section{Manuscript History}

Received: 12 February 2017

Final Accepted: 16 March 2017

Published: April 2017

Key words:-

Breastfeeding, breast related problems, mastitis, breast engorgement, sore nipples, early initiation

\section{Abstract}

Objective:- To study the various problems related to breastfeeding in the postnatal wards that inhibited breast feeding of mother-infant dyads, with focus on breast-related problems, its time of onset and also to determine if early initiation of breast feeding decreased these problems.

Methods:- It is a one year hospital based observational study of mother-infant dyads (August 2014-Augsut 2105) done from data collected from a semi-structured questionnaire of 250 mother-infant dyads admitted in postnatal wards in the Niloufer Hospital for Women and Children, Hyderabad, affiliated to Osmania Medical College.

Results:-The total number of mother-infant dyads in the study were 250. 151 mothers out of $250(60 \%)$ started breastfeeding their babies within one hour of delivery. $64.4 \%$ mother infant dyads had various problems related to breast feeding, the most common problem reported by the mothers is perceived inadequacy of breast milk $(20 \%)$, loose stools in $13 \%$, breast engorgement in $11 \%$ mothers, mastitis in $8 \%$ and sore nipple/inverted nipple in $3.5 \%$. The breast related problems occurred around 3-7 days. The incidence of these problems are less in early initiator breast feeding group compared to late initiators.

Conclusion:- The breast feeding problems encountered in this study can be easily treated with simple supportive measures and some medications. Early initiation of breast feeding leads to decreased breast related complications. Proper antenatal and postnatal lactation counselling will motivate the mothers to continue exclusive breastfeeding for 6 months.

Copy Right, IJAR, 2017,. All rights reserved. 


\section{Introduction:-}

the policy statement the American Academy of Pediatrics (AAP) ${ }^{1}$ reaffirms its recommendation of exclusive breastfeeding for the first six months, followed by breastfeeding in combination with the introduction of complementary foods until at least 12 months of age, and continuation of breastfeeding for as long as mutually desired by mother and baby. In 1990, at a joint meeting of the WHO/ UNICEF meeting in Florence, Italy, the Innocenti Declaration ${ }^{2}$ was made. In this document, the WHO/ UNICEF emphasized the need for a social mobilization to reinforce a 'breastfeeding culture'. The United Nations Children's Fund (UNICEF) has estimated that exclusive breastfeeding in the first six months of life can reduce under-five mortality rates in developing countries to $13 \%{ }^{3}$. The World Health Organization ${ }^{4}$ recommends that breastfeeding be initiated within 1 hour of birth. The National Guidelines on Infant and Young Child Feeding ${ }^{5}$ (NGIYCF) also recommends to initiate breast feeding in first hour after birth and to continue exclusive feeding up to 6 months.

Despite these recommendations, only $39 \%$ of newborns in the developing world are, put to the breast within one hour of birth, and only $37 \%$ of infants under-six months of age are exclusively breastfed. The findings by WBTi $2012^{6}$ India report of 2012 that the rate of early initiation of breastfeeding was $40.5 \%$ and the rate of exclusive breastfeeding for six months was $46.8 \%$.

Barriers to breastfeeding are multifactorial and include socioeconomic status, education levels, misperceptions, social norms and maternal health especially in underserved women. Yngvel and Sjo Estro $\mathrm{Em}^{7}$ (2001) suggest that the initiation and duration of breastfeeding depends on socio-demographic, psycho-social, or health-care related determinants.

In general, breastfeeding problems can be divided into three categories; breast related problems, socio-demographic issues and pregnancy related factors. In this study, the focus is on breast related problems. Breast related problems are Inverted or Flat Nipples, Fullness and engorged breasts, Sore nipples and cracked nipples, Plugged duct, Mastitis, Breast Abscess, and Candidiasis.

\section{Objective:-}

The objective of the study was to examine the various problems related to breastfeeding and their time of onset in the postnatal wards of a tertiary care hospital with focus on early initiation of breast feeding and its association with these problems.

\section{Method:-}

This was a hospital based observational study in Niloufer Hospital for Women and Children, Hyderabad, which is a tertiary care hospital attached to the Osmania Medical College. The study received approval from the College Ethics Committee.

The data set was collected from 250 mother-infant dyads admitted in postnatal wards between August 2014 and August 2015. Only mother who were willing to participate in the study and healthy term and late pre-term babies (gestational age between 34 weeks, and 36 weeks and 6 days) only were included in the study. Written consent was taken from the mothers. Mothers not willing, sick neonates admitted in NICU and preterm neonates with gestational age less than 34 weeks were excluded.

Data was collected by interviewing mothers using a semi-structured questionnaire. The initial background questions covered demographic, social and economic status, and educational status of the mother. The proforma also included antenatal history, current feeding practices, feeding problems in the present pregnancy, and whether the mother received any feeding advice or not. This information was obtained from the mother in her native language and clinical examination was done with the help of the staff nurse and female postgraduate students wherever necessary, after taking due permission from the mother.

\section{Statistical Analysis:-}

A master chart was prepared with all the data that was collected and transferred to MS Excel, which was used to summarize the data and create the graphs and charts. Open EPI Info-version 7.0 software used for analysis of data. Chi squared $\left(\mathrm{X}^{2}\right)$ test and P-values were calculated to know the relationship between early initiation and breastrelated problems. 


\section{Results:-}

The total number of mother infant dyads in the study (n) were 250. 150 mothers were primipara and 98 were multipara. 164 babies delivered vaginaly and 86 were delivered by LSCS. Term babies were 211 and late preterm babies were 39 . Out of the 250 dyads, 89 mothers or $35.6 \%$ of the sample, did not encounter any problems in breastfeeding. This is shown in Table 1.169 of the mothers or $64.6 \%$ of the sample experienced some form of breastfeeding problem.

Table 1:-

\begin{tabular}{|c|c|c|}
\hline Description & $\mathrm{n}=250$ & $\%$ \\
\hline No Problem & 89 & $35.6 \%$ \\
\hline Breast engorgement & 28 & $11.2 \%$ \\
\hline Mastitis & 19 & $7.6 \%$ \\
\hline Perceived inadequacy of milk & 50 & $20 \%$ \\
\hline Sore nipple & 9 & $3.6 \%$ \\
\hline Loose stools in baby & 33 & $13.2 \%$ \\
\hline Inverted nipple & 6 & $2.4 \%$ \\
\hline Oral thrush & 2 & $0.8 \%$ \\
\hline Other problems* & 9 & $3.6 \%$ \\
\hline Mother does not know when to start & 5 & $2 \%$ \\
\hline
\end{tabular}

*Other problems included breast related--blocked duct (1), breast abscess (1), eczema (1), absent breast (1) and no milk (3) and non-breast related--cleft palate in baby (2)

The time of onset of breastfeeding problems:-

Most of the problems in the present study are reported between $3^{\text {rd }}$ and $7^{\text {th }}$ postnatal day, shown in Figure 1.
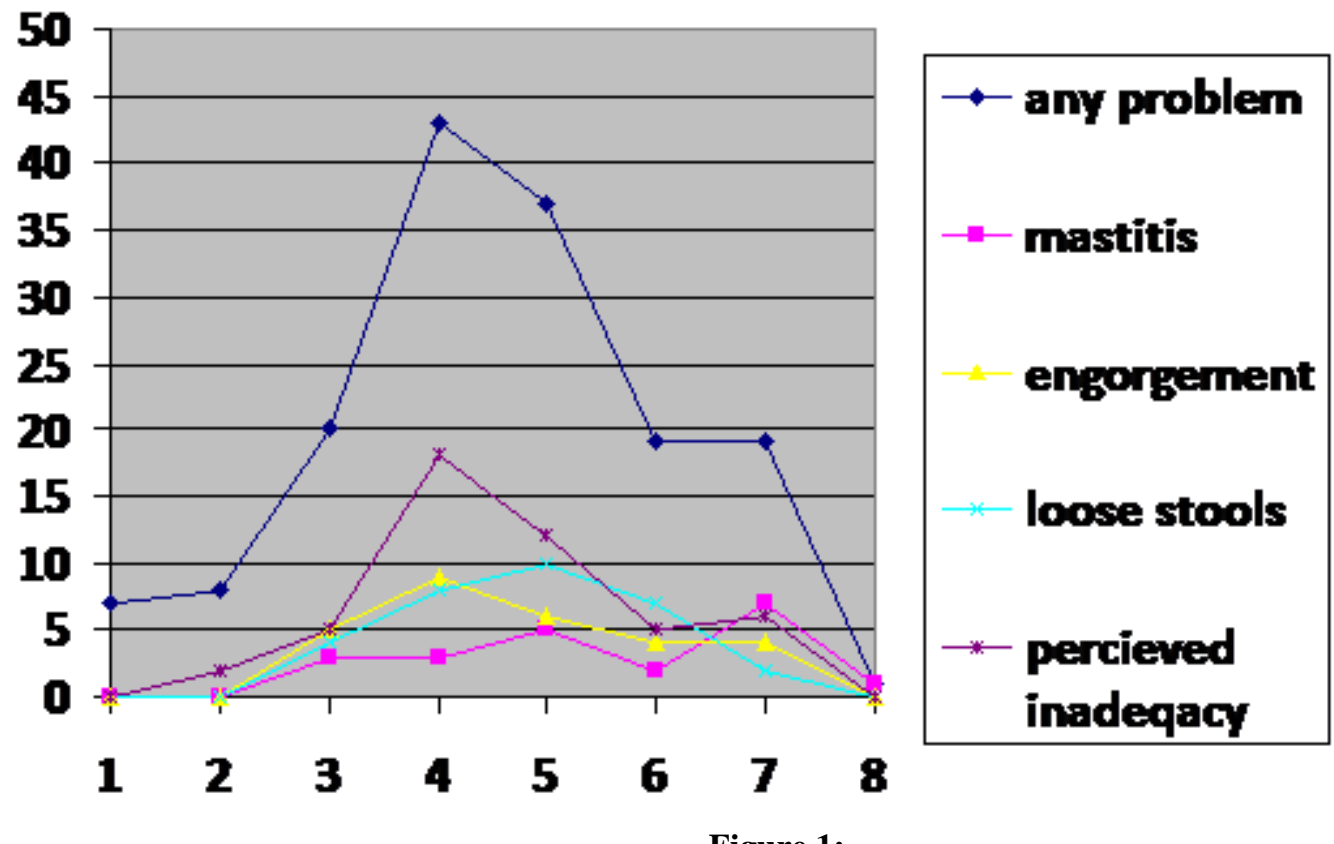

Figure 1:-

Early initiation of breastfeeding: 151(60.4\%) mothers out of 250 started breastfeeding their babies within one hour of delivery, shown in Figure 2. 


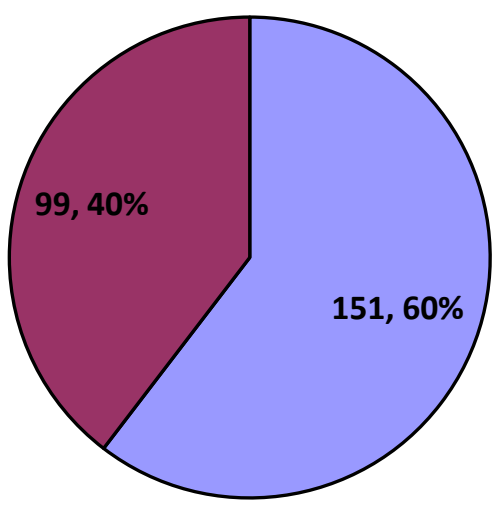

口initiated within 1 hou

late intiation

Figure 2:-

Relationship Between Early Intiation Of Breastfeeding And Breastfeeding Problems:-

Relationship between early initiation of breastfeeding and breast engorgement (Table 3).

Table 3:-

\begin{tabular}{|l|l|l|l|l|}
\hline $\begin{array}{l}\text { Early initiation of } \\
\text { breast milk }\end{array}$ & Engorgement Present & No Engorgement & Total & $\mathrm{X}^{2}$ and P-value \\
\hline Yes & $14(9.2 \%)$ & 137 & 151 & $\mathrm{X}^{2}=1.42$ \\
\hline No & $14(14.1 \%)$ & 85 & 99 & $\mathrm{P}=0.232$ \\
\hline Total & 28 & 222 & 250 & \\
\hline
\end{tabular}

The Chi-square and P-value show that breast engorgement is more common in those who didn't initiate breastfeeding early than those mothers who do early initiation of breastfeeding within one hour with a significant Pvalue.

Relationship between early initiation of breastfeeding and mastitis (Table 4).

Table 4:-

\begin{tabular}{|l|l|l|l|l|}
\hline Early initiation of breast milk & Mastitis present & No mastitis & Total & $\mathrm{X}^{2}$ and $\mathrm{p}$ value \\
\hline Yes & $8(5 \%)$ & 143 & 151 & $\mathrm{X}^{2}=2.5$ \\
\hline No & $11(12 \%)$ & 88 & 99 & $\mathrm{P}=0.08$ \\
\hline Total & 19 & 231 & 250 & \\
\hline
\end{tabular}

Mastitis is more common in those who do not initiate breastfeeding within one hour than those who initiate early with a significant $\mathrm{P}$-value.

Relationship between early initiation of breastfeeding and perceived inadequacy of breast milk (Table 5).

Table 5:-

\begin{tabular}{|l|l|l|l|l|}
\hline $\begin{array}{l}\text { Early initiation of breast } \\
\text { milk }\end{array}$ & $\begin{array}{l}\text { Perceived } \\
\text { inadequacy }\end{array}$ & $\begin{array}{l}\text { No perceived } \\
\text { inadequacy }\end{array}$ & Total & $\mathrm{X}^{2}$ and P-value \\
\hline Yes & $19(12 \%)$ & 132 & 151 & $\mathrm{X}^{2}=13.1$ \\
\hline No & $31(31 \%)$ & 68 & 99 & $\mathrm{P}=0.0002$ \\
\hline Total & 50 & 200 & 250 & \\
\hline
\end{tabular}

Perceived inadequacy is more common in those who do not initiate breastfeeding early with a very significant $p$ value.

Relationship between early initiation of breastfeeding and cracked nipples (Table 6).

Table 6:-

\begin{tabular}{|l|l|l|l|l|}
\hline $\begin{array}{l}\text { Early initiation of } \\
\text { breast milk }\end{array}$ & $\begin{array}{l}\text { Cracked nipple } \\
\text { present }\end{array}$ & $\begin{array}{l}\text { Cracked Nipple not } \\
\text { present }\end{array}$ & Total & $\mathrm{X}^{2}$ and $\mathrm{p}$ value \\
\hline Yes & $4(2.6 \%)$ & 147 & 151 & $\mathrm{X}^{2}=0.99$ \\
\hline No & $5(5 \%)$ & 94 & 99 & $\mathrm{P}=0.31$ \\
\hline Total & 9 & 241 & 250 & \\
\hline
\end{tabular}


Cracked nipples are more common in those who do not initiate breastfeeding early with a significant $\mathrm{p}$ value (Yates $\mathrm{p}$ value $=0.31$ ).

\section{Discussion:-}

The common breast related breastfeeding problems encountered in the present study are perceived inadequacy of the breast milk, breast engorgement, mastitis and cracked nipples which can be easily treated with simple supportive measures and few medications. Most of these problems are noticed between $3^{\text {rd }}$ and 7 th post-natal day. If not addressed appropriately, these problems can lead to early cessation of breastfeeding, leading to irreversible short and long term consequences in both the mother and infant.

Many studies have shown that addressing these early postnatal problems can result in increased rates of exclusive breastfeeding at six months. The American Academy of Pediatrics ${ }^{1}$ has recommended that "all breastfed newborns should receive an evaluation by a provider knowledgeable in lactation management within 2 to 3 days post discharge".

A number of researchers have studied the problems affecting breastfeeding. A descriptive study by Lamontagne, Hamelin and St-Pierre ${ }^{8}$ (2008) identified painful nipples/breasts, low milk supply and latching difficulties as the three most frequent major breastfeeding problems. Foxman, D'Arcy, Gillespie, Bobo and Schwartz ${ }^{9}$ (2001) wrote that in their USA study the percentage of mothers with mastitis was 9.5\%. Marsha Walker ${ }^{10}$ (2000) in an IBCLC study found rates of breast engorgement between 20 percent and 85 percent. However, these studies did not cover the full range of issues that impact breastfeeding and also are related to western countries.

In the Indian context, Sithara Suresh et $\mathrm{a}^{11}$ wrote about experiences in a tertiary care centre in North India regarding predictors of breastfeeding problems in the first post-natal week. A study was also done by Eidelman and others ${ }^{12}$. A comparative table of our study with that of the other studies is shown in Table 7.

Table 7:-

\begin{tabular}{|l|l|l|l|}
\hline Breastfeeding problem & This Study & Sithara Suresh and Others & Eidelman Al and others \\
\hline Breast engorgement & $11.2 \%$ & $13 \%$ & $35 \%$ \\
\hline Mastitis & $7.6 \%$ & $0.3 \%$ & \\
\hline Nipple related & $6.00 \%$ & $17.8 \%$ & $44 \%$ \\
\hline Perceived inadequacy & $20 \%$ & & $20 \%$ \\
\hline Pacifier use & & $54 \%$ & $22 \%$ \\
\hline No Problem & $35.6 \%$ & $27.5 \%$ & \\
\hline
\end{tabular}

The findings of the North India study by Sithara Suresh et $\mathrm{al}^{11}$ are similar to the findings in our study. Like our study, a study by Wagner ${ }^{13}$ and others show that breastfeeding problems are more common on day 3 and day 7 . Similar study by Mallikarjuna and Banapurmath ${ }^{14}$ showed that the maximal onset of breastfeeding problem was noted in the first two weeks of neonatal period.

The rate of early initiation of breastfeeding in our study is $60.4 \%$, which appears to be a good rate. The data reported by other studies on the rate of early initiation is shown in Table 8 below.

Table 8:-

\begin{tabular}{|c|c|}
\hline & Initiation of feeding < 1 hour \\
\hline Present study & $60.4 \%$ \\
\hline${\text { NFHS }-3^{15}}^{15}$ & $23 \%$ \\
\hline WBTi $^{6}$ & $40.5 \%$ \\
\hline Ajay Kumar $^{16}$ & $30 \%$ \\
\hline
\end{tabular}

Our study also shows that early initiation of breast feeding has statistically significant less breast related problems, which will encourage and motivate the mothers to continue breast feeding. The problem of breast engorgement in early initiation group was $9 \%$ compared to $14 \%$ in late feeder group. Mastitis is 5\% in early initiators compared to $12 \%$ in late feeders. Perceived inadequacy of milk is $12 \%$ in early initiators and $31 \%$ in late initiators while cracked nipple is $2.6 \%$ in early initiators and $5 \%$ in late initiators. 
An exhaustive search of scholarly articles was made and studies related to early initiation and reduced breast related problems were not found. It was reported that early initiation of breastfeeding reduced the risk of infant diarrhoea in Egypt $^{17}$. In Nepal ${ }^{18}$, early initiation of breastfeeding was associated with reduced neo-natal mortality. Baker, Sanei and Franklin ${ }^{19}$ have reported that breastfeeding within the first hour followed by early exclusive breast feeding improves the health and survival status of new-borns. Therefore, this is an interesting area for future research.

\section{Conclusions:-}

The common breastfeeding problems encountered in the present study are perceived inadequacy of breast milk, loose stools after each feed, breast engorgement, mastitis and cracked nipples. Breast related problems are a significant component of breast feeding problems which occurred between 3-7 postnatal days. These are the reversible causes and if not recognised and treated early, can lead to irreversible short and long term consequences in both the mother and infant. Thus the importance of addressing these issues by trained medical staff, and lactation counselors if available. Most problems just need reassurance and giving confidence to the mother while problems like mastitis and oral thrush can be treated by medications.

Early initiation of breast feeding has shown to decrease breast related feeding problems, which will reinforce and motivating the mothers to continue exclusive breast feeding of their baby. All the studies referenced have shown that addressing these early postnatal problems can result in increased rates of exclusive breastfeeding at six months. We have no hesitation to recommend early initiation of breast feeding and strongly support Baby Friendly Initiative ${ }^{20}$ (BFHI) which will implement practices that protect, promote and support breastfeeding.

This was a hospital based study hence the results may not be applicable or extended to the general population. Follow up was not done in the present study so the breast feeding problems that could arise after discharge from the hospital were not studied.

\section{References:-}

1. "Breastfeeding and the Use of Human Milk". Pediatrics. March 2012, Vol. 129 / Issue 3. https://www.aap.org/en-us/about-the-aap/aap-press-room

2. The Innocenti Declaration on the protection, promotion and support of breastfeeding. Geneva: WHO/ UNICEF, 1990.

3. United Nations Children's Fund (UNICEF): Progress for Children: A Child Survival Report Card2004. Accessed 15 April 2012.

4. Nutrient adequacy of exclusive breastfeeding for the term infant during the first six months of life, WHO 2002.

5. National Guidelines on Infant And Young Child Feeding: Ministry of Women and Child Development (Food and Nutrition Board) Government of India 2006.

6. WBTi INDIA 2012 report. http://www.worldbreastfeedingtrends.org/ GenerateReports/report/WBTi-India2012.pdf.

7. Yngve1, A and Michael Sjo Èstro Èm, M. (2001). "Breastfeeding determinants and a suggested framework for action in Europe". Public Health Nutrition: 4(2B), 729-739 (2001)

8. Lamontagne C, Hamelin A-M, St-Pierre M. (2008). "The breastfeeding experience of women with major difficulties who use the services of a breastfeeding clinic: a descriptive study". International Breastfeeding Journal. 2008; 3:17.

9. Foxman, B., D'Arcy, H., Gillespie, B., Bobo, J.K. and Schwartz. K. (2001). "Lactation Mastitis: Occurrence and Medical Management among 946 Breastfeeding Women in the United States. American Journal of Epidemiology 2001; Volume 155, Issue 2 pp. 103-114.

10. Walker, M. (2000). "Breastfeeding and Engorgement". Breastfeeding Abstracts, November 2000, Volume 20, Number 2, pp. 11-12.

11. Suresh S., Sharma, K.K., Saksena M., Thukral A., Agarwal R., and Vatsa M. (2014). "Predictors of breastfeeding problems in the first postnatal week and its effect on exclusive breastfeeding rate at six months". Indian Journal of Public Health. 2014 Oct-Dec. 58 (4): 270-3. doi: 10.4103/0019-557X.146292.

12. Eidelman AI, Schanler RJ, Johnston M, et al (2012). "Breastfeeding and the use of human milk". Pediatrics (2012) 129 (3). Available at: www.pediatrics.org/cgi/content/full/129/3/e827

13. Wagner, EA, Chantry CJ, Dewey KG, and Nommsen-Rivers LA (2013). "Breastfeeding concerns at 3 and 7 days postpartum and feeding status at 2 months". Pediatrics (2013) Oct; 132 (4): e865-75. 
14. Mallikarjuna, C.R. Banapurmath, Shobha Banapurmath and Nirmala Kesaree .Breastfeeding Problems in First Six Months of Life in Rural Karnataka. Indian Pediatrics 2002; 39:861-864.

15. Ministry of Health and Family Welfare: National Family Health Survey 3, India, 2007.[http://mohfw.nic.in/nfhs3/CD.htm].

16. Ajaykumar, G., Patil, VM, Tengliar, SG., Reddy, S. and Vijayanath V. (2011). "Breast feeding practices among mothers in urban field practice area of M.R. Medical College Gulbarga". Journal of Pharmaceutical and Biomedical Sciences 2011; vol.04, issue 04: pp1-3

17. Clemens, J., Elyazeed, R. A., Rao, M., Savarino, S., Morsy, B. Z., \& Lee, Y. J. (1999). "Early initiation of breastfeeding and the risk of infant diarrhoea in rural Egypt". Pediatrics, 104(1), e3-e3.

18. Mullany, L. C., Katz, J., Li, Y. M., Khatry, S. K., LeClerq, S. C., Darmstadt, G. L., \& Tielsch, J. M. (2008). "Breast-feeding patterns, time to initiation, and mortality risk among newborns in southern Nepal". The Journal of Nutrition, 138(3), 599-603.

19. Baker, E. J., Sanei, L. C., \& Franklin, N. (2006). "Early initiation of and exclusive breastfeeding in large-scale community-based programmes in Bolivia and Madagascar". Journal of Health, Population and Nutrition, 530539.

20. Ten steps to successful Breastfeeding- UNICEF/WHO Baby Friendly Hospital Initiative (BFHI).Initiation of breastfeeding by breast crawl. http://breastcrawl.org/10steps.shtml. 